
\title{
Obesity as an Etiological Factor in Erectile Dysfunction: An Insight into the
}

\section{Literature}

\author{
Akhil K Padmanabhan*
}

Practitioner, Researcher \& Health advisor, India

*Corresponding author: Akhil K Padmanabhan, Practitioner, Researcher \& Health advisor, India

\section{Abstract}

Obesity is one of the most common lifestyle disorder in the present day life. Obesity refers to excessive body weight in relation to the height and age of the individual. It is studied to be linked to many systemic disorders such as cardiovascular diseases, hypertension and other serious illness. Erectile dysfunction is such a disorder that is said to be linked to obesity. This article is an insight into the association of obesity with erectile dysfunction with the available evidences in the literature.

Keywords: Erectile dysfunction; Obesity; Overweight; Sexual disorders

\section{Introduction}

According to the World health organization (WHO), worldwide obesity has almost tripled since 1975. Most of the world's population live in countries where overweight and obesity kills more people than underweight. 38 million children under the age of 5 were overweight or obese in 2019. Over 340 million children and adolescents aged 5-19 were overweight or obese in 2016 [1]. Among all the lifestyle diseases, Obesity is one disease that affects almost all aspects of general health. However, the evidences are insufficient to clearly point out the association and the possible mechanism of the biological link between them.

Erectile dysfunction affects a major population across the world. It is a sexual disorder characterized by the inability to attain and maintain an erection during sexual activity [2]. It is more common in men above 40 years of age [3]. Several factors such as neurogenic, cavernosal, psychological, hormonal and drugs are studied to cause ED, [4] however, the most commonly explained pathophysiology is vascular disease [5].

\section{Obesity and Endothelial Dysfunction}

Obesity can cause an increase in the inflammatory burden in the body. It is associated with an increase in the visceral adipose tissue in the body. This is a dynamic tissue that is considered to be directly associated with cardiovascular risk. The adipose tissue secretes the hosy modulators and signaling chemicals mainly proinflammatory cytokines that contributes to systemic inflammation. These include interleukin (IL)-6, IL-1b, plasminogen activator inhibitor-1 (PAI-1), tumor necrosis factor-a (TNFa), angiotensinogen, angiotensin-converting enzyme, vascular endothelial growth factor, and serum amyloid A. All of them are associated with damage to the endothelium resulting in vascular disorders [6]. The relationship between erectile dysfunction and vascular disorders is well established. The inflammation brought about by systemic inflammation can lead to endothelial dysfunction that can lead to ED.

\section{Reduced Testosterone Levels}

Reduced levels of testosterone in serum is one of the metabolic alterations associated with obesity [7]. Visceral obesity can disrupt the endocrine function. This is done by reducing the levels of Luteinizing hormone (LH) and testosterone that leads to in hypogondoropic hypogonadism. Furthermore, the increased aromatase activity of peripheral and visceral fat down regulates the 
testosterone production and increases the levels of estradiol (E2). This further increases the fat deposition contributing to obesity and further worsening of erectile dysfunction. 6 Thus reduced androgen levels can cause ED or increase the severity of the existing ED.

\section{Influence of Obesity on Developing Other Co Morbidities} That Contribute To Ed

Evidences from the literature has already established that obese individuals are at increased risk of developing several metabolic and vascular disorders such as hypertension, diabetes, hyperlipidemia and atherosclerosis. All of these co morbidities per se can have an effect on the vascular functions. Diabetes is associated with increased incidences of vascular disorders that can cause hampered circulation due to endothelial dysfunction [8-10]. This can have a direct association with ED [11].

\section{Treatment of Ed and Obesity}

Lifestyle modification is one of the major strategy in the successful management of obesity and obesity induced ED. Poor outcomes with the definitive treatments of ED can be associated with obesity and associated co morbidities. It is of greater importance to rule out the possible impact of such disorders in the management of ED.

\section{Conclusion}

Obesity can be a risk factor in development of ED. Successful management essentially involves examination for excessive body weight and associated disorders that could be possibly contributing to the condition.

\section{References}

1. https://www.who.int/news-room/fact-sheets/detail/obesity-andoverweight

2. Montague DK, Jarow JP, Broderick GA, Dmochowski RR, Heaton JP, et al (2005) Chapter 1: The management of erectile dysfunction: An AUA update. J Urol 174(1): 230-239.

3. Krane RJ, Goldstein I, Saenz de Tejada I (1989) Impotence. N Engl J Med 321: 1648-1659.

4. Chiurlia E, D’Amico R, Ratti C, Granata AR, Romagnoli R, et al. (2005) Subclinical coronary artery atherosclerosis in patients with erectile dysfunction. J Am Coll Cardiol 46(8): 1503-1506.

5. Heidelbaugh JJ (2010) Management of erectile dysfunction. Am Fam Physician 81(3): 305-312.

6. Traish AM, Feeley RJ, Guay A (2009) Mechanisms of obesity and related pathologies: androgen deficiency and endothelial dysfunction may be the link between obesity and erectile dysfunction. The FEBS journal 276(20): 5755-5767.

7. Svartberg J, von Muhlen D, Sundsfjord J, Jorde R (2004b) Waist circumference and testosterone levels in community dwelling men. The Tromso Study. Eur J Epidemiol 19(7): 657-663.

8. Prager R, Wallace P, Olefsky JM (1987) Hyperinsulinemia does not copensate for peripheral insulin resistance in obesity. Diabetes 36(3): 327- 334

9. Hubert HB, Feinleib M, McNamara PM, Castelli WP (1983) Obesity as an independent risk factor for cardiovascular disease: A 26-year follow-up of participants in the Framingham Heart Study. Circulation 67(5): 968977.

10. Evans DJ, Murray R, Kissebah AH (1984) Relationship between skeletal muscle insulin resistance, insulin-mediated glucose disposal, and insulin bindings: effects of obesity and body fat topography. J Clin Invest 74(4): 1515-1525.

11. K Padmanabhan Akhil. Efefctive treatment of erectile dysfunction: What you can expect from your urologist. Bee-potent.

*Corresponding author: : Akhil K Padmanabhan, E-mail: drakhilkp@gmail.com

Next Submission with BGSR follows:

- Rapid Peer Review

- Reprints for Original Copy

- E-Prints Availability

- Below URL for auxiliary Submission Link: https://biogenericpublishers.com/submit-manuscript/ 